\title{
Peer Observation: A Professional Learning Tool for English Language Teachers in an EFL Institute
}

\author{
Ejaz Ahmed ${ }^{1, *}$, Zaimuariffudin Shukri Nordin ${ }^{2}$, Sayyed Rashid Shah ${ }^{3} \&$ Mansoor Ahmed Channa ${ }^{4}$ \\ ${ }^{1}$ English Language Institute, University of Jeddah, Saudi Arabia \\ ${ }^{2}$ Faculty of Cognitive Sciences and Human Development, University Malaysia Sarawak, Malaysia \\ ${ }^{3}$ English Language Institute, King Abdul-Aziz University, Jeddah, Saudi Arabia \\ ${ }^{4}$ Quaid-e-Awam University of Engineering, Science, and Technology, Nawabshah, Pakistan \\ *Correspondence: English Language Institute, University of, Jeddah, Saudi Arabia. Tel: 966-508-281-805. E-mail: \\ u2ejaz@gmail.com
}

Received: March 9, 2018

Accepted: March 21, 2018 Online Published: April 3, 2018

doi:10.5430/wje.v8n2p73

URL: https://doi.org/10.5430/wje.v8n2p73

\begin{abstract}
The key aim of this study is to explore the perceptions of English as foreign language (EFL) teachers about peer observation as a tool for professional development that is implemented in an English Language Institute of a Saudi Arabian university. This paper reviews literature on peer observation to develop a conceptual and theoretical understanding of peer observation systems in different contexts. It utilizes a mix-method approach and applies a questionnaire and semi-structured interviews as data collection tools. Questionnaire is used to get information about EFL teachers' perceptions whereas semi-structured interviews provide an insight into their practices in the form of peer observation and future amendments for PD. The participants share their lived experiences who consider the current practice of peer observation a consistent professional challenge due to several factors, i.e. their lack of autonomy in deciding about the peers, trust deficit between administration and EFL teachers, rarely held pre-observation conferences due to the loads of teaching hours, observers' insufficient training and qualifications in conducting PO, and the element of threat and insecurity. Based on the findings, recommendations are made to improve the existing peer observation system for the benefit of the EFL teachers, English language learners and the institute.
\end{abstract}

Keywords: peer observation, professional development, mixed methods, EFL context

\section{Introduction}

Teachers' development (TD) is not a new concept and it has been accepted as an academic measure since the time of Socrates (Charlotte \& McGreal, 2000). Richards and Farrell (2005) believe that teachers need to be able to engage in self-reflection and evaluation, developing specialized knowledge and skills about many aspects of teaching, expanding their knowledge base about research, theory, and issues in teaching, taking on new roles and responsibilities, such as supervisor or mentor teacher, teacher-researcher, or materials writer and developing collaborative relationships with other teachers. As the field of language teaching changes rapidly both as a profession and trends with respect to new educational paradigms and institutions, it faces new challenges as a result of changes in students' needs, curriculum and tests. Consequently, the language teachers require regular opportunities to develop themselves professionally (Wong, 2004; Wallace, 2001).

Institutions around the world have embraced new ways of developing teachers professionally that includes, peer observation (PO), formal observation and professional development (PD) programs (workshops, seminars, presentation of research papers). In the context of the current research, PO is considered a way of professional development of EFL teachers. It is assumed that this approach has compensated for the teachers' lack of training in the Saudi context. However, there is a perception, that Saudi Arabia as compared to other Gulf States offers more training opportunities to EFL teachers (Syed, 2003). On the other hand, Al-Hazmi (2003) posits that very little teacher training is available in the KSA despite the dire need for it. Despite this contradiction, it is established that professional learning and development are needed at every level and EFL teachers should make efforts to keep 
themselves abreast of new developments in the field of TESOL. In addition, institutions can also offer formal courses to EFL teachers in a bid to meet their professional learning needs. However, Shah, Hussain and Nasseef (2013) found the existing PD programmes in the Saudi EFL context inadequate and inappropriate to address the professional learning needs of the EFL teachers. Due to this drawback, EFL teachers often rely on collaborative work by observing each others' classes and giving feedback that help in improving their pedagogical practices.

Apart from PD programmes and courses offered at this context, the institute has a rigorous observation scheme that aims to assess teachers' performances in classrooms. Ideally, such a system should help EFL teachers to enhance their instructional practices; however, Shah and Al-Harthi (2014) has associated a number of issues with the current observation system in place, which include; a top-down observation approach, threat and insecurity, untrained observers and observers' subjective approach towards classroom observation. These challenges force EFL teachers to think out of the box and prepare themselves for the challenge of formal observation that counts towards their overall ranking in the institute. One way of taking on this challenge is to undertake peer observation in order to see each others' performances objectively and overcome their weaknesses in a non-threatening and friendly environment. It is important to mention that in the context of this research, EFL teachers observe each other twice a year and university considers this activity as an appropriate system to develop teachers professionally. However, there is a serious dearth of research on the effectiveness of such practices in the Saudi EFL context. Hence, this research aims to explore the PO practice of EFL teachers in the Saudi context and understand the perceptions of teachers of the PO system.

The following research questions aim to find out the main aim of this research:

1. What are the views and beliefs of the teachers about peer observation? Do they consider them as tools for their PD or not?

2. To what extent do EFL teachers consider peer observation helpful in their professional development?

\section{Literature Review}

Professional development is described by Mann (2005) as "a career oriented (activity) and has a narrower, more instrumental and utilitarian remit" (p.104). That is, development of a teacher is an individual moral commitment (Miller, 2004). It includes personal, moral and value dimensions that can be encouraged and integrated in both training and education programmes (Mann, 2005). In the field of TESOL, PD explores teacher learning that leads to improved instruction in the classroom and "one cannot restrict language teacher education to one set of rules or one ideology" (Johnstone, 2004, p. 651). There are many ways available to orchestrate the PD of the teachers in language teaching which cannot be restricted to a particular approach. For example, self-monitoring, teacher support groups, team teaching, journal writing, teaching portfolios, case analysis, peer observation, analysis of critical incidents, peer coaching, workshops, and action research (Richards \& Farrell, 2005) are some of the approaches to PD. It is a process which occurs over a period of time and leading to the professional growth for the teachers. It is an important part of ongoing teacher education and is central to the role of teachers.

\subsection{The significance of Professional Development in a Workplace}

PD is important for teachers not only to understand the ongoing process of development of their professional roles, but it also helps teachers to understand the process of developing the second language. It gives an outlook to understand the roles of teachers with regard to different students in class. For example, in mixed ability classes, teachers take different steps to explore and help the learning of the students (Allwright, 2005). Connected to professional development, teachers review the theories and principles of language teaching and lead them to revise what works well and why (Wilson et al., 2011). The PD enables teachers to review different teaching practices like reflective analysis of teaching practices which helps them learn and cooperate in the form of self-observation and reflection (Richards \& Farrell, 2005). Studies suggest that more reflective teachers are better than less ones because the former makes decisions on time to respond to the changing needs of learners (Yost et al., 2000; McMeniman et al. 2003). PD may go beyond personal and individual reflection. For example, with PD, new trends and theories can be explored to familiarize teachers to develop subject matter knowledge for instance pedagogical grammar and composition theory. Moreover, PD provides the foundation to explore schools and language programs and eventually it organizes and manages the programs (Richard \& Farrell, 2005).

As the significance of professional development is well established in literature, it is vital for institutions to provide teachers with formal and informal learning opportunities in their workplace context. Drawing on work in general education, teacher educators admit that teachers are not empty vessels to be filled with pedagogical and theoretical 
skills; rather they have prior knowledge, personal values and beliefs which guide the teaching in the classroom and inform them about new trends in teaching (Freeman \& Johnston, 1998). As teachers need to know about new development, knowledge and technologies at different workplaces, the role of the context becomes crucial. The role of the school/workplace in organizing PD has been divided into two categories of teacher PD, namely extracted and embedded. Extracted PD welcomes the outsiders' specialized knowledge (Flint et al. 2011), whereas embedded development talks about insiders' expert knowledge (Desimone, 2011; Opfer \& Pedder, 2011). In this study, we concentrate on embedded teacher PD which enables teachers to learn from one another within their own school contexts (Webster-Wright, 2009; Desimone 2011; Opfer \& Pedder, 2011). One form of embedded learning is peer observation (PO), which is discussed in the following section.

\subsection{Peer Observation}

PO of teaching is a collaborative developmental activity in which professionals offer support while observing each other teach, explaining and discussing on what was observed; reflecting on understanding the feelings, procedures, actions and feedbacks, and trying out new ideas in the class while teaching (Bell, 2005). Similarly, it is a process by which one teacher observes the teaching of another teacher. In fact, the observer is expected to provide constructive feedback after the teaching session (Karagiorgi, 2012). Moreover, it is said that PO is a technique which provides chances to teachers in order to reflect, think critically and get feedback. Consequently, it helps teachers to collaborate and share the learning experiences which can be beneficial for both the observer and observee (Motallebzadeh, et al., 2017).

PO can be used for multi purposes in education. Malderez (2003) discussed four main purposes for observation: for professional development, for training, for evaluation, and for research. For the purpose of this study, we will concentrate on developmental aspects of PO.

In teaching, the aim of PO is to provide an opportunity for novice teachers to see what more experienced teachers do and how they do it when they teach a lesson. PO also offers an opportunity to experienced teachers to see how someone else deals with many of the same teaching problems they encounter on daily basis. Observing another teacher may also trigger reflections about one's own teaching. The observer can provide an "objective" view of the lesson to the teacher who is being observed (Richards \& Farrell, 2005). In addition, PO allows participating teachers to start dialogue, encourages open debates on their teaching and supports risk taking in teaching which will affect teaching and learning of the teachers and students (Donnelly, 2007). In tandem, the research has considered that PO provides sustainable professional developmental chances to teachers to update their teaching strategies (Santos, 2016).

Researchers and authors associate a variety of challenges with the process of PO. It can be challenging for teachers to write down critical reflection, explore successful and unsuccessful teaching experiences and provide and accept feedback (Bell, 2005). Similarly, Motallebzadeh, et al. (2017) posits that PO lead to anxiety and lack of confidence with someone observe and examine your performance with critical views. This challenge can be addressed amicably if mutual trust is there among teachers. Furthermore, while PO may contribute to individual development, it is not always seen as enhancing wider developmental initiatives (Hammersley-Fletcher \& Orsmond 2004). In the same way, Shortland (2004) notified that the ambiguous nature of PO usually includes performance and developmental debate (Cosh, 1998). The performance based observation is extensively applied within the context of higher education. In this activity, one teacher of faculty visits another's classroom and renders judgment (Carter, 2008). In such cases, observee teachers get defensive and often feel threatened by the presence of a stranger into their classes while novice teachers react to this situation by hiding the weaknesses (Carter, 2008) and try to follow the institutional requirements during observations (Gosling, 2005).

Several studies (e.g. Bell, 2001; Lomas \& Nicholls, 2005) suggest that the PO may be used as a developmental tool rather than an evaluative activity. The observee can decide the goals of the PO in order to receive meaningful feedback (Donnelly, 2007; Mann, 2005). As a result, teachers will be able to follow the developmental aim of PO. In tandem with this, Gosling (2005) explains that developmental approach of PO facilitates reflection on the effectiveness of the participants' own teaching and helps them improve the quality of learning and teaching, promotes discussion and disseminates good practice and increases awareness with regard to student experience of learning. The more we share common experiences with others, the greater possibility is to learn and broaden the horizons of our thinking and knowledge (Webb, 1996), which ultimately affects the learning of observer, observee and students. Therefore, we can say that PO is a very effective and powerful tool to develop if colleagues use it for developmental purposes and provide constructive feedback to each other. It will also help them to have experience of other teachers while they are in action (Marshall, 2004). Consequently, teachers will have great chances during PO to 
challenge the accepted wisdoms and self-concepts and transform their practices (Peel, 2005).

Developmental PO can help teachers with improved instruction in the classes, development of confidence among teachers to teach, learn more about teaching and transformation of educational perspectives (Bell, 2005). Moreover, colleagues build trusting relationship by promoting collaboration to improve teaching techniques and methods. PO can also promote the modeling of appropriate teaching practices from observer to those being observed. More respect for the approaches of colleagues' guides to the development of collegiality (Quinlan \& Akerlind, 2000). It brings teachers together and share who might not normally have a chance to interact (Richards \& Farrell, 2005).

\subsection{The Procedure of Peer Observation}

The key goal of observation is to learn from the experience of observation (Richards \& Farrell, 2005). To achieve it, the observer cannot simply depend on memory but he also needs to know the procedures to record information during PO. The following are three specific but interdependent activities for the purpose of PO.

\subsubsection{Pre-observation Meeting}

Observations can be successful experience if both the observer and observee make the experience constructive (Ewans, 2001). The more specific the observed teacher can be, the more useful information observer is likely to provide (Sheal, 1989). The observee decides what is to be observed and how it will be observed and what he will hope to gain from the observation. Both the parties can have a common, if they have good relationship. Farrell (2001) calls the relationship between observer and observee during the PO as "critical friendships: colleagues helping each other develop" (p.368). In a pre-observation meeting, observer and observee recognize the suitability of classroom activities for example, group work, a lecture or discussion (Donnelly, 2007) to collect the basic information about the class. Furthermore, subjects like overall teaching schedule; the arrangement of the observation session(s) and timetable for feedback session; the learning outcome for the agreed session(s); the assessment schedule and criteria for observation are some of the basic requirements of the pre-observation session in which observer and observee discuss the matters extensively to get the benefit out of it (Donnelly, 2007). It also provides the observers an opportunity to know beforehand the culture and expected problems in the classroom which really helps the them to reflect on the expected events (Richards \& Farrell, 2005).

\subsubsection{Observation of the Lesson}

The PO is carried out at a previously agreed time and it may be helpful to inform the students about the observation in advance and assure them that the purpose is to assist teacher's or observer's professional skills and not to evaluate the students (Donnelly, 2007). During the lesson, the focus of the observer should be on students' motivation, listening, understanding and learning (Donnelly, 2007). For observer, it is vital to be part of experience without being drawn into debate or dialogue (Martin \& Double, 1998). Since the observee takes the initiative for this process, therefore, observer should be prepared to let the critical friendship unfold naturally (Farrell, 2001). The observer and observee decide on how to record the session using the appropriate paperwork. The preferred style to record the observation is written narrative in the form of field notes (Richard \& Farrell, 2005). In this respect, Montgomery (1999) advises to record classroom observations with the help of a sampling frame as it enables the observer to record the factual events involving rapid writing. The observer with written record should be able to give feedback accurately and with clear evidence for any comments to the observee. In carrying out a written narrative, it is advisable not to write everything that happens during the lesson (Richard \& Farrell, 2005). The language used should be objective and precise, and avoid writing judgment. The observer should find "the optimal ways to provide guidance that inspires rather than disheartens" (Stillwell, 2009, p, 354).

\subsubsection{Post Observation Conference}

It is crucial to have post observation sessions by focusing on three key points viz: a review of the criteria and agreements, an analysis of learning outcomes of the observed lesson and a scrutiny of the lesson plan (Donnelly, 2007). The observers give feedback to observee on the observed lesson and they decide how the information gained from the observation will be discussed and used in future.

For Donnelly (2007), post observation meeting is a "giving and receiving feedback model" (p. 122). Gosling (2005) replaces this notion of "giver" and "receiver" with dialogue model in which both observer and observee are regarded as equal and mutual beneficiaries of the process. Ewans (2001) suggests that feedback should generally be an affirming and encouraging process. The feedback could be given either immediately after the observation session or a day after the observation at an agreed time and place (Rhodes et al., 2004). Instant recall to the observed session may be helpful in the formative assessment process. However, observees may be over or underwhelmed by their performance and may not be able to listen or respond to their observers' comments. Whereas the following day 
feedback will give more time to observee in order to provide a thorough response to what was observed. It also offers observers some time to think about how they will present their comments and perhaps orchestrate some sort of priority of what was observed (Rhodes et al., 2004). However, we would suggest that it is not advisable to delay the feedback for long because observee is involved in day to day teaching and may not be able to recall all the events successfully due to the similar situations they face every day in the classes.

\section{Methodology}

This research has adopted a mixed-method approach to investigate EFL teachers' perceptions of peer observation practice in a Saudi EFL institute. The key rationale for adopting a mixed-method approach was to achieve a greater depth and understanding of the research phenomenon by utilizing qualitative and quantitative methods. Scholars and advocates of mixed-method designs believe that the combination of quantitative and qualitative tools help researcher to present a better understanding of the research problem(s) and question(s) than relying on a single method independently (Creswell, 2012; Frels \& Onwuegbuzie, 2013; Hong \& Espelage, 2011).

As interviews and questionnaires are commonly used data collection tools in mixed-method designs (Gillham, 2005; Gillham, 2007), we aimed to exploit these techniques in order to gather rich and valid data. Questionnaires and interviews suited the nature and purpose of this study.

First, we considered a questionnaire useful to get information from the whole group of EFL teachers because questionnaires are the best survey techniques to gather quantitative data (Gillham, 2005). Second, we focused on five EFL teachers to collect qualitative data, which was done through semi-structured interviews. Semi-structured interviews can provide important insights into people's experience, beliefs, perceptions, and motivations if interviewer conducts them properly by allowing respondents sufficient flexibility to probe some aspects in depth, then respondents lead in much the same way as they do in an open interview (Heigham \& Croker, 2009).

\subsection{Participants}

The participants of this study were EFL English teachers working in the same context. At the ELI, there are more than 50 EFL teachers from 20 different countries. In this study, only 13 EFL teachers participated and responded to the survey questionnaire. Out of 13 respondents, there are 4 Tunisians, 3 Pakistanis, 2 Malaysians, 2 Indians, 1 Egyptian and 1 Sudanese. For the purpose of quantitative data, the questionnaire was sent to all the teachers via email, whereas the qualitative data were collected from five purposively chosen EFL teachers. Before the process of data collection started, ethical approval was acquired from the administration and participants were explained the aim of the study and they were given a right of withdrawal at any stage of the study.

\subsection{Design of Questionnaire and Semi-Structured Interviews}

The use of a questionnaire facilitated the process of collecting quantitative data as it was easy to apply and saved us time (Dornyei, 2003; Gillham, 2007). However, it must be admitted that the questionnaire has its demerits. Questionnaires are generally limited in nature as participants are asked to choose pre-selected responses (Gillham, 2007). Accordingly, questionnaire designers have to be careful or they may unconsciously guide participants to unexpected answers without realizing it (Gillham, 2007). Secondly, participants sometimes do not provide the correct information due to administrative pressures. To compensate for this weakness, semi-structured interviews were utilized to explore emerging areas of interest in order to get more detailed information and clarification on official policies. The key questions covered the approaches behind PD and observations of teachers, official aims of the observation and development, potential disadvantages and results of teachers' development and observation at the Institute. Open-ended questions allowed interviewees to answer without inhibition, resulting in more reliable, relevant and rich data.

Several issues arise when discussing the use of questionnaires as a research tool. The first difficulty is to ensure the truthfulness of the answers of respondents (Gillham, 2007). Because questionnaires are impersonal, respondents may not respond to questionnaire with honesty (Gillham, 2007). Yet these problems any type of research may face and can be avoided through proper planning and design (Gillham, 2007). To address this problem, ensuring participants' confidentiality can help in providing honest answers. Electronic mails with clear research purpose were sent to teachers. "If respondents are clear about what you are trying to find out, they are much more likely to respond appropriately indeed, at all" (Gillham, 2007, p. 38). Participants are fully protected and their original name(s) are replaced with pseudonym(s) to avoid any future complications. Two copies of consent forms were provided; one each for the participant and the researcher. 


\section{Findings and Discussion}

This section discusses teachers' responses to the research questionnaire in four main sections. Each section addresses the overall findings and implications of the participants' responses under the following headings:

- Background Information

- Teacher Development

- $\quad$ Peer Observation (I. Teachers' experience in PO, II. Stages of PO, and data collection tool)

- $\quad$ Final comments to improve PO

In addition to that, we report the teachers' responses to the questions during the interview in order to get in-depth information about peer observation and professional development. The total number of participants is thirteen $(\mathrm{N}=13)$; however, in instances where participants chose not to respond to an item, the total number of respondents will differ. Each section of analysis includes a discussion of the results.

\subsection{Background Information}

Most of the participants have Master degrees and considerable difference with regards to teaching of English in general and in the KSA; therefore, they are not new to the local culture and environment. The EFL teachers possess background knowledge and have relevant experience in the field of teaching.

Teaching experience and life-long learning enable EFL teachers to approach their work differently from novices because they can understand anticipated problems in classrooms and find ways to solve those problems effectively. However, Richards and Farrell (2005) have mentioned that it is not enough for teachers to depend on themselves in their development and there should be collaboration of internal and external sources of reflection to maximize development and improvement. With this note, the next section presents different TD activities which teachers prefer to use to develop.

\subsection{Teacher Development}

B1: Which of the following do you think can help in developing EFL teachers professionally?

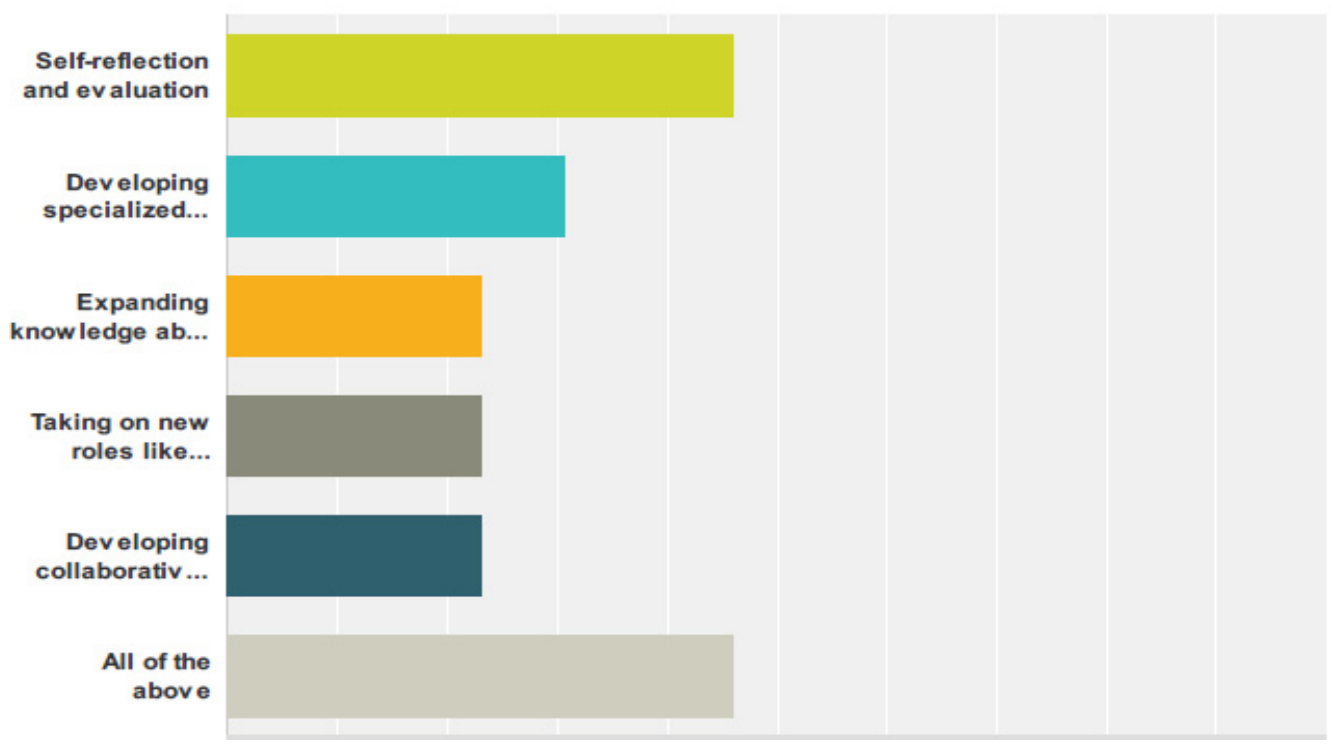

Figure 1. Role of Different Activities to Develop Teachers

Diagram 1 indicates that EFL teachers have a strong belief in the role of self-reflection and evaluating in promoting development, while the other points being accepted more or less equally as helpful. Furthermore, with collaboration teachers develop the habit of reflecting and evaluation. It is also noted that the reflective approach gives a greater role to personal experience in the development process of teachers (Crandall, 2000). 


\subsection{School and Teachers' Approaches Towards TD}

Table 1. Approaches to Teacher Development by the Teachers and School

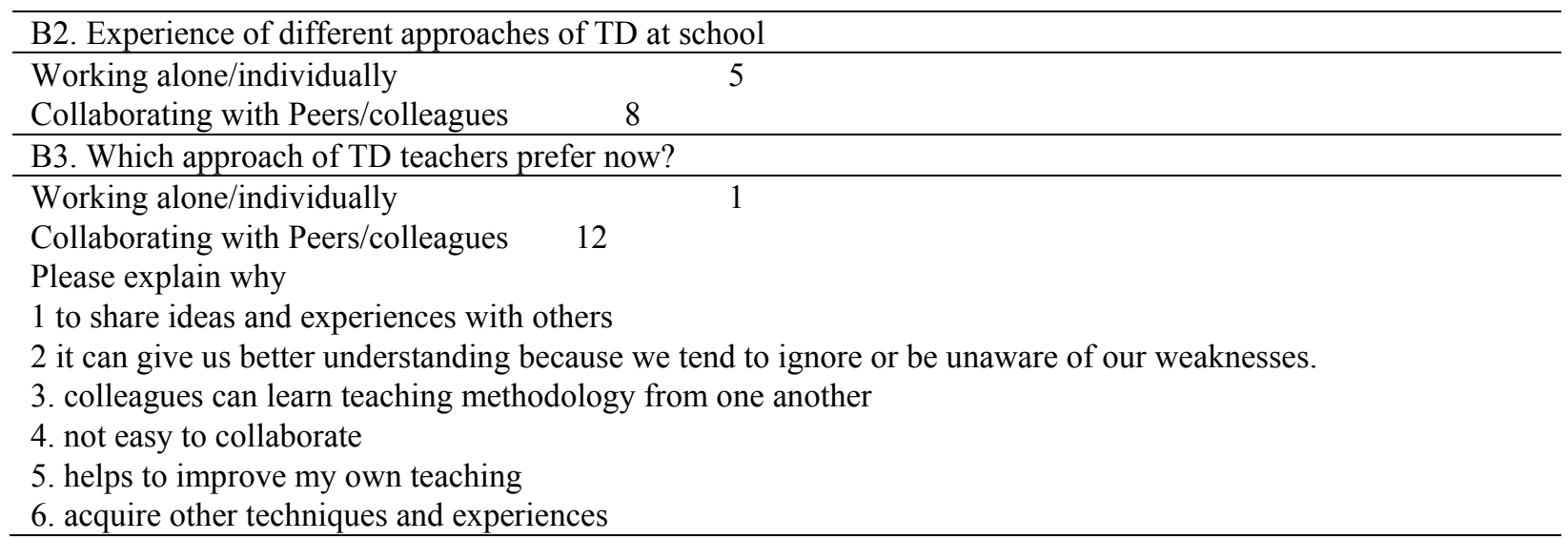

The results from table 2 indicate that an overwhelming majority supported the idea of working with peers. It is interesting to note that participants desire to work collaboratively. However, during an interview, a participant responded that working in collaboration is not an easy task in the Saudi EFL context. It has risks such as judgmental reports on PO which can disrupt a teacher's progress and his relationship with colleagues. This can be minimized if the aims of $\mathrm{PO}$ are clear at the outset.

\subsection{Different Types of TD Activities and Teachers' Participation}

B3: TD activities teachers prefer to participate.

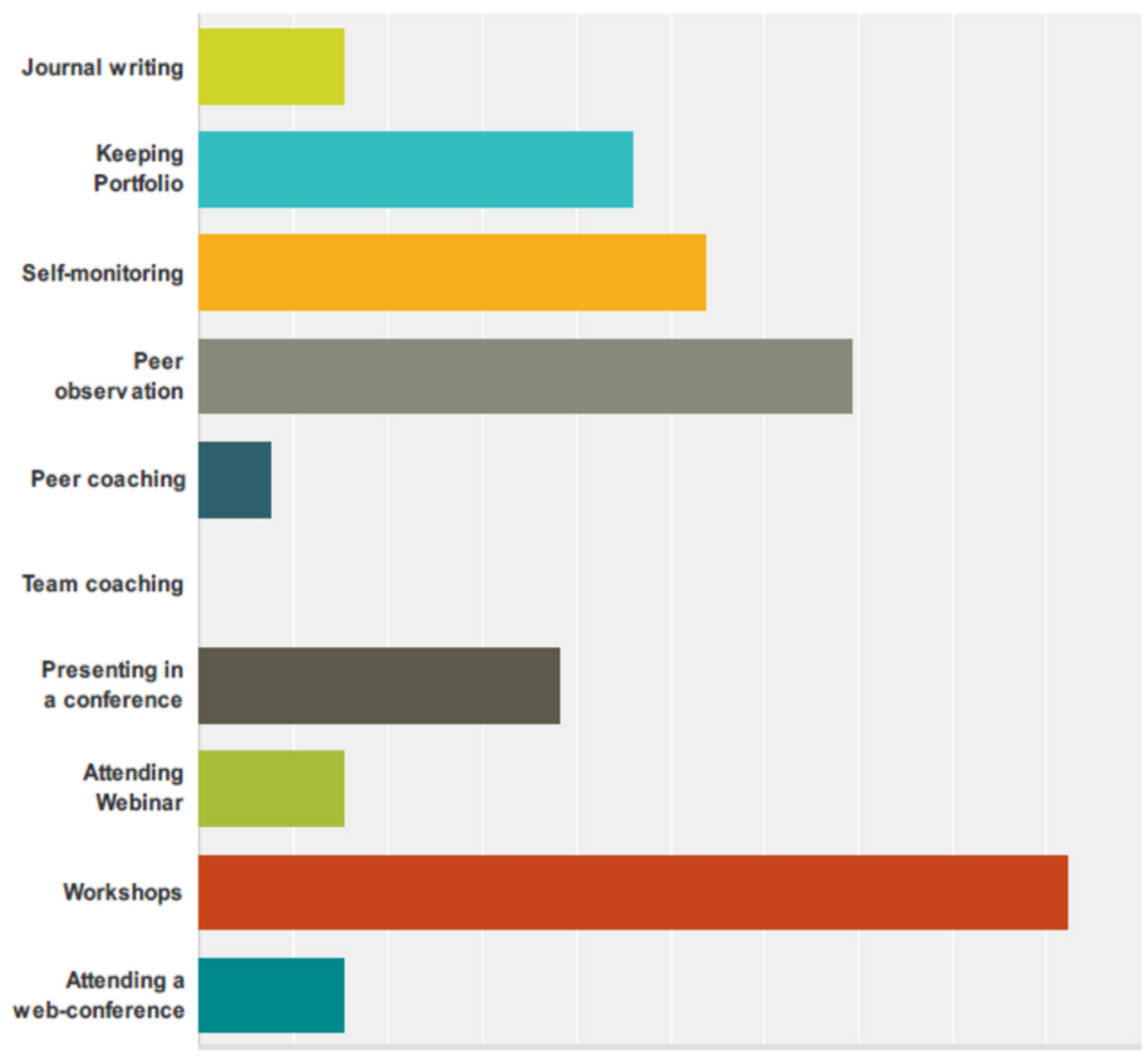

Figure 2. Teacher Development Activities 
The results in figure 2 show that a majority of the teachers are interested in attending workshops offered at the institute; the next most frequent, and of interest to this study, is peer observation. On the other hand, there is little interest in coaching, mentoring or peer and teamwork. The interest for attending workshop and PO strongly suggests that EFL teachers desire opportunities to interact and discuss with others, an important benefit of teacher professional development through collaboration and collegiality (Crandall, 2000; Wright \& Bolitho, 2007).

A vast majority (11) of EFL teachers think that they are compelled to join PD activities with a minority (3) that believes that teachers develop on their own. This clarifies that top-down approach is applied in the campus in order to develop teachers and EFL teachers' professional learning needs are not considered beforehand. The questionnaire also sought to get insights into how EFL teachers perceive PD activities in their teaching context. Mixed responses were noted as teachers responded with different frequency (a lot, to some extent, rarely) to participate in TD activities.

Overall, the responses of teachers were positive towards PD activities. However, EFL teachers seem to have a lack of trust in the administration and to bridge this gap, the need of the time is perhaps to negotiate and collaborate before arranging TD activities in order to retain the trust of the teachers. This is similar to what Shah (2014) has found that EFL teachers and administrators in the Saudi EFL context have trust deficit, mainly due to bureaucratic leadership structures.

\subsection{Peer Observation}

\subsubsection{Teachers' Experiences of Peer Observation}

Participants were asked about their experience of training for PO, their right to choose a peer and whether they had an initial meeting or not. The table below shows their responses.

Table 2. Teachers' Experiences in Peer Observation

\begin{tabular}{lll}
\hline Item & Yes & No \\
\hline Received any training? & 8 & 5 \\
Right to choose peer? & 2 & 11 \\
Initial meeting? & 9 & 4 \\
\hline
\end{tabular}

To justify these answers, some participants said that the training they had about PO was two years ago and that they were not familiar with the new trends in TESOL. This implies that teachers require up-to-date information about PO. Most of the teachers lack knowledge and training of observing classes. Insufficient training finds its roots in judgmental reports which make the lives of observee teachers difficult (Shah \& Al-Harthi, 2014; Namaghi, 2011). Five respondents who said 'no' cannot be ignored. If they are not familiar with PO procedure, it will be a futile to ask them to do the PO because in some cases in the past the teachers had bad discussions.

The data also show that an overwhelming majority (8) favored the idea of discussing the plan with the observer which clarify that teachers really wanted to improve with the help of PO. Edge (2002a) calls this 'cooperative development'. This proves that teachers are positive about PO and they want to discuss the plan/program before the lesson.

With regards to overall usefulness of PO, all thirteen EFL teachers found it helpful; however, nine of them thought it was only helpful to some extent. All the responses verify that teachers want to collaborate and improve with the help of PO. They like to do PO and believe that PO is one of the tools to develop.

\subsubsection{Teachers as Observers}

As observers, the participants commented on taking notes during the observed lesson, sometimes 'to evaluate' and sometimes to focus on what the observee wanted. The focuses mentioned were class managements, time, rapport with learners and teaching methodology. Providing feedback to the teacher observed was also frequently mentioned. Almost all the participants considered the main role of observer as guiding the observee's development and improving their practices. Also, it is equally significant for observer's development and evaluation of the peers. An overwhelming majority agreed to the supportive role to develop teachers. Overall, it is deemed as a reciprocal process of learning for observers and observees.

It is quite interesting to mention that the observers believe to guide observee's development and this identifies that PO is a tool of PD and it helps to improve teaching. This verifies the beliefs of the teachers towards PO and its impact on their professional learning. Data suggest that majority of the teachers believe PO is a tool for the PD. 


\subsubsection{While Peer Observation}

\subsubsection{Teachers as Observees}

The quantitative data indicate that out of twelve people, six used the adjective 'nervous' in order to express themselves as observees. From the results, it is evident that teachers were under pressure due to their apprehensions about the procedure of PO. For example, one teacher expressed himself as 'if peer observation is for evaluation, he would hate it. But if it is for development, he would feel great'. Despite a collaborative effort, teachers feel concerned and cautious about their performance in their classes due to the lack of trust between teachers and administration. Teachers do not feel comfortable and consequently underachieve in the presence of an observer. Due to these pressures, teachers underperform and eventually affect the learning outcomes of the students. It implies that teachers are not fully aware of the objectives of PO and there is a communication gap between the administration and EFL teachers. To address this in a better way, teachers and administration might adopt a flexible approach and discuss the procedure to decide a plan and follow it with a positive approach. This will allow EFL teachers to be more open to listen to criticism of their observer which will create a constructive environment for teachers to improve.

\subsubsection{Teachers as Observers}

As observers, a large majority (10) of EFL teachers thought to focus on issues that teacher considered important for their teaching. Although six of them were only interested in collecting information about an observed lesson; whereas, two agreed to take part in classroom activities for the sake of their own learning. Five participants believed that the process was PO used mainly for evaluating teachers' performance.

From the results, it is shown that all EFL teachers in this study has an idea of the role of an observer during PO; however, only two of them think they will evaluate other teachers to help them with their performances as novice ones often lack sufficient training and skills. To minimize the idea of evaluating, teachers can be guided to do PO with the help of some training workshops or courses.

\subsubsection{The Use of Observation Rubric}

The findings suggest how teachers as observers recording the lessons and collected data while observing their peers. Majority (10) takes notes while observing others and 5 teachers like to tick a rating scale form. Regarding the aim of collecting data, seven EFL teachers supported the idea of focusing on specific points of a lesson as it will allow observees and observers to look for a particular area of development. However, five participants believed that general information about PO would help to improve their practice of observing teachers. From the findings, it can be inferred that EFL teachers in general were not very clear about the main purpose of PO.

Teachers' reaction to observation tool as an observer and observee gives useful insights into their practices. The data suggest that teachers as observers do not concentrate on teachers' actions while writing or recording in class. They find it difficult to write reports while observing someone. On the other side, one teacher remarked as it is very easy to provide report with the availability of an observation tool. Similarly, another commented that it was easy to use data collection tools because he was aware of the curriculum. Thus, familiarity with the observation tool is considered important to effectively practice peer observation. One of the reasons why teachers found it difficult to concentrate on writing while observing a peer was the descriptive nature of the observation tool which required a lot of explanation to justify the claims about the performance of the observee teachers. The core word which came out from these responses was "difficult".

Nevertheless, it is evident from the data that PO helps teachers to develop which is the main aim of this research. It also gives the real picture of one's teaching which can be used as foundation for future development.

\subsubsection{After the Peer Observation}

The next stage of PO was observers' and observees' discussion after the lesson. Eight EFL teachers supported the idea of getting feedback from the observer. While seven teachers preferred to reflect on the lesson in the presence of observer. In spite of diverse preferences, all participants indicated that post observation session takes place after the observed lesson. Overall, one impression has emerged from the results is to reflect on the lesson immediately after the lesson because teachers preferred to discuss the observed lesson in order to identify their weaknesses to develop. However, three EFL teachers liked to have feedback sessions immediately after the observation whereas ten of them preferred to have feedback sessions at a later time and date.

During the post observation meetings, data suggest that observers lead the session and observees are not encouraged to have their say in the session. In an ideal situation, the observer would listen to the observee first to give him time to think and reflect on his lesson delivery. This verifies the fact that top-down approach is applied to develop 
teachers. All the participants have consented that feedback should be used in a constructive way and for the future development of EFL teachers.

Table 3. Teachers' Reaction to Feedback Session

\begin{tabular}{|c|c|c|c|c|}
\hline \multicolumn{5}{|l|}{ Feedback session } \\
\hline \multicolumn{5}{|c|}{ C21: Feelings of the observee when receiving feedback from an observer? } \\
\hline Answer Choice & Responses & Answer Choices & \multicolumn{2}{|c|}{ Responses } \\
\hline Angry & 0 & Worried & \multicolumn{2}{|c|}{0} \\
\hline Comfortable & 4 & Satisfied & \multicolumn{2}{|c|}{6} \\
\hline Disappointed & 0 & Defensive & \multicolumn{2}{|c|}{2} \\
\hline \multicolumn{5}{|c|}{ Total: 12} \\
\hline \multicolumn{5}{|c|}{ Other (Please specify): It depends. } \\
\hline \multicolumn{5}{|c|}{ C22. Do you participate in the feedback session a lot, to some extent, a little or not at all? } \\
\hline Answer choices & Responses & Answer choices & & \\
\hline A lot & 4 & A little & & \\
\hline To some extent & 9 & Not at all & & \\
\hline \multicolumn{5}{|l|}{ Total: 13} \\
\hline \multicolumn{5}{|c|}{ C23. What is important give feedback to an observee teacher? } \\
\hline \multicolumn{4}{|c|}{ You lead the discussion and observee listens and defends } & 6 \\
\hline \multicolumn{4}{|c|}{ Observee leads the discussion and you listen and respond accordingly } & 7 \\
\hline \multicolumn{4}{|c|}{ Observee leads the discussion and you ignore his points } & 0 \\
\hline \multicolumn{4}{|c|}{ Observee leads the discussion and you tell him the good points only } & 0 \\
\hline \multicolumn{4}{|c|}{ Total } & 13 \\
\hline \multicolumn{5}{|c|}{ C24. Overall, general experience of feedback by peers after observation? } \\
\hline \multicolumn{2}{|c|}{ It is constructive } & 13 & & \\
\hline \multirow{2}{*}{\multicolumn{2}{|c|}{$\begin{array}{l}\text { It is judgmental/prescriptive/general. } \\
\text { Total: } 13\end{array}$}} & 0 & & \\
\hline & & & & \\
\hline \multirow[t]{3}{*}{ Can you explain why? } & & \multirow{3}{*}{\multicolumn{3}{|c|}{$\begin{array}{l}\text { We can learn from our mistakes. } \\
\text { It provides the guidance for future development } \\
\text { You judge better your teaching when observed. }\end{array}$}} \\
\hline & It pr & & & \\
\hline & & & & \\
\hline
\end{tabular}

In table 12, EFL teachers' reaction to feedback session gives an impression that teachers are pleased with the outcome of feedback sessions. Most of the teachers reckon that feedback session is a collaborative activity and teachers participate in this session; however, the frequency of their participation varies from observation to observation. From table 12,100\% teachers recognized the feedback session by peers is a constructive session and considered it a source of guidance which can be beneficial for the development of EFL teachers.

As shown in Table 3, top-down approach has been adopted and EFL teachers do not have a choice to select peers for their observation. The teachers receive their schedules electronically with the name of a peer observer. Due to the teachers' lack of voice, they are not at ease to deal with such situations. It is noted that if observers and observees do not collaborate, it will not help teachers to develop; rather they would consider this activity intrusive that challenges academic freedom (Lomas \& Nicholls 2005). On the contrary, if peer observations are conducted under supportive conditions, there are numerous benefits of peer observation of teaching, such as improvement in teaching practice and the building of confidence to teach and learn more about teaching (Bell, 2005), more respect for the approaches of colleagues (Quinlan \& Akerlind, 2000).

The data show that teachers would prefer to have a revised tool for observation purposes, which could help them record teachers' actions in their classrooms. Perhaps an information collection tool with choices like excellent, good, satisfactory, needs improvement and dissatisfactory may help the observers to tick boxes in order to concentrate on various aspects of teaching. However, teachers require training in this field. In addition, teachers require time to prepare the reports and share them. We would suggest that teachers should not delay the reports for too long. In this way, there is a risk of forgetting different important points. 


\subsection{Improving the Peer Observation Scheme}

\subsubsection{Teachers' Responses to the Effectiveness of PO}

All the participants (13) consider PO as an effective way of improving teaching practices. It confirms that teachers like PO and they want to continue with this.

Table 4. Effectiveness of PO and Future Prospects

\begin{tabular}{ll}
\hline D2. To make PO more effective what changes would you like to suggest? & 10 \\
\hline Choosing a peer to observe and to be observed & 3 \\
Increasing teachers' responsibility & 8 \\
Organizing an initial meeting before PO & 0 \\
Welcome the presence of Administration during PO & 6 \\
More specific observation form & 5 \\
Having workshop or course to prepare teachers for PO & 4 \\
Improving constructive feedback meeting & \\
Total Respondents: 13 & \\
Other (Please specify) & \\
Observation should not determine teachers' contract's renewal & \\
\hline
\end{tabular}

Table 14 offers insight into teachers' efforts that make PO more effective in their institution. Teachers endorsed that they should choose a peer to observe and to be observed. No one appreciated the interference of administration during PO. Teachers wanted to organize it by themselves. Furthermore, results show that EFL teachers are well aware of the importance of $\mathrm{PO}$ and they want to do it. However, they want themselves to be responsible for the process of peer observation. It verifies that EFL teachers support a bottom up approach to improve the system of peer observation.

\subsubsection{Teachers' Interviews and Their Responses}

This section of the paper presents and discusses the data collected through semi-structured interviews with five EFL teachers to further explore and authenticate their responses to the questionnaire.

\subsubsection{Purpose of Peer Observation}

Generally, the purpose of peer observation in the context of this study is to professionally develop as English language teachers. To the EFL teachers on this study, PO means one teacher comes to another's class and gives constructive feedback in a non-threatening environment. However, some teachers would like to develop their abilities to utilize the observation tool in an effective way, which highlights the shortcomings of the existing PO system. From the responses, it is evident that teachers consider PO a useful tool of professional development of EFL teachers.

\subsubsection{Procedure of Peer Observation}

EFL Teachers on this study endorsed that workshops and seminars are some of the steps school should provide to improve teaching. Teachers should collaborate with the consent of administration. Overall, an impression of collaboration is put forward by the teachers to develop professionally.

Teachers also expressed that the role of the administration should be developmental and like a facilitator. In our context, administration decides about observers and schedules. Teachers use written narrative, recordings, writing notes, and tick the questionnaires in the classroom to collect the data. But this data is not deemed reliable in the eyes of administration and they verify the data with the help of videos, which they make in classrooms. One teacher expressed that any slip of tongue that is recorded can be used against the teacher which eventually affects the renewal of the contract. Overall, the video recording is a frustrating experience for the EFL teachers. This validates a lack of trust between teachers and administration. In order to make PO more effective and helpful for the development of EFL teachers, it is necessary to develop trust between the teachers and administration. Perhaps the first step for teachers and administration is to negotiate the procedures and objectives of peer observation scheme.

\subsubsection{Attitude Towards Peer Observation}

The interviews data indicate that all the participants felt it was not as threatening as formal observation because a friend was coming to observe with no intention of damaging the observee except one participant who found the 
process fearful. He said that he was reluctant because he was not clear about the intention of the administration and every lesson was different and one performs differently on different occasions. Only one teacher was excited about recording the sessions while others were reluctant due to the consequences of unforced errors. This concern could be linked to the termination of teachers in the past on the basis of video recorded classes, which stimulated such insecure feelings and teachers believed that such recording could be used against them too. This means that EFL teachers have apprehensions about PO procedure. They prepare their lessons to defend themselves in front of observers in order to save jobs.

\subsubsection{Teachers' Role in Peer Observation}

As an observer, teachers supported the idea of writing reports and as an observee, all the participants wanted to perform naturally in the class and try to do their best in order to learn from each other. All the teachers validated the idea of being fair in their roles as observers as one teacher said he played the role of a guide. As an observee, teachers performed in a relaxed way during their teaching sessions because a friend was observing with no intention to use the written reports against them. From the interview data, it can be inferred that EFL teachers wanted to share and cooperate through peer observation. However, this cooperation can only benefit the EFL teachers and administration if they work collaboratively.

\subsubsection{Challenges of Peer Observation}

Regarding the challenges that emerged as a result of interview sessions with EFL teachers, different teachers had different opinions. Except for one teacher who was relaxed and did not have any challenge of PO, rest of them expressed their concerns. One teacher was under pressure due to the lack of punctuality on part of the students, which would affect his performances. For example, any student who is late to the class is entitled to attend the class according to the school policy. In either case, teachers are at the receiving end as it is counted against teachers. In addition, one teacher found time management as a challenge, whereas another teacher considered the observation tool as a challenge in the system of PO. These concerns and challenges can be used as a guiding line for the administration that can provide a better environment for future PO based on the teachers' input. If any help is required by the teachers, it should be provided to make the process smooth and fruitful, which will contribute to the effectiveness of the institution.

\subsubsection{Suggestions to Improve Peer Observation Scheme}

Apart from the suggestions emerged in the questionnaire, the interview data adds to these points. To make PO more effective, teachers believe that written reports should be used by the teachers only without any recording. The main aim of PO should be to improve pedagogical practices and learning outcomes of the students. All the teachers believe that PO is purely teachers' activity and it should be processed by the teachers only in order to make it more effective, thus, administration should not participate in it. Moreover, schools can help/facilitate teachers by allowing them to perform their roles in PO with autonomy. This will give them a chance to select their peers for the purpose of observing teachers, writing the reports and sharing them among themselves. If a teacher performs well, he should be acknowledged and appreciated. Teachers should collaborate with each other and should decide their roles in this matter. This will create opportunities for observers and observees to learn from each other's experiences and collaborate with rest of EFL teachers by visiting each other classes. It may help EFL teachers to improve which eventually help students to ascend the ladder of success with confidence.

\section{Conclusion}

In this paper, we have attempted to investigate the effectiveness of peer observation and how it can help teachers develop professionally in the Saudi EFL context. It is necessary for teachers to understand the usefulness of PO and for administration to support the process of PO. The establishment of a systematic PO programme in which teachers' opinions are valued about peer selection may be a better option which will contribute to the EFL teachers' professional growth. We assume that individual teachers visiting each other classes with their consent can have a useful impact on the teaching community within their workplace. Therefore, administration should work towards systematic implementation of PO scheme as a tool of promoting professional learning and growth. Although other strategies for professional development, such as writing journals or diaries, keeping portfolios and team-teaching may also be useful, these have not been investigated in this context, which can be a researcher's endeavour in the future. Moreover, investigation is required to see how various approaches can be implemented in this context to facilitate EFL teacher development in the Saudi EFL context. 


\section{References}

Al-Hazmi, S. (2003). EFL Teacher Preparation Programs in Saudi Arabia: Trends and Challenges. TESOL Quarterly, 37(2), 341-344. https://doi.org/10.2307/3588509

Allwright, D. (2005). From teaching points to learning opportunities and beyond. TESOL Quarterly, 39(1), 9-31. https://doi.org/10.2307/3588450

Bell, M. (2001). Supported reflective practice. A programme of peer observation and feedback for academic teaching development. The International Journal for Academic Development, 6(1), 29-39. https://doi.org/10.1080/13601440110033643

Bell, M. (2005). Peer observation partnerships in higher education. Milperra, NSW: Higher Education Research and Development Society of Australasia.

Carter, V. (2008). Five steps to becoming a better peer reviewer. College Teaching, 56(2), 85-8. https://doi.org/10.3200/CTCH.56.2.85-88

Charlotte, D., \& McGreal, L. T. (2000). Teacher Evaluation to Enhance Professional Practice. Educational Testing Service.

Cosh, J. (1998). Peer observation in higher education - A reflective approach. Innovations in Education and Training International, 35(2), 171-6. https://doi.org/10.1080/1355800980350211

Crandall, J. (2000). Language teacher education Annual Review of Applied Linguistics, 20, 34-55. https://doi.org/10.1017/S0267190500200032

Creswell, J. W. (2012). Educational research: Planning, conducting, and evaluating quantitative and qualitative research (4th ed.). Boston, MA: Pearson Education, Inc.

Day, C. (1999). Developing teachers: The challenges of lifelong learning. Psychology Press.

Desimone, L.M. (2011). A primer on effective professional development. Phi delta kappan, 92(6), 68-71. https://doi.org/10.1177/003172171109200616

Donnelly, R. (2007). Perceived Impact of Peer Observation of Teaching in Higher Education. International Journal of Teaching and Learning in Higher Education, 19(2), 117-129.

Dornyei, Z. (2003). Questionnaires in Second Language Research: Construction, Administration, and Processing. Lawrence Erlbaum Associates, Inc: New Jersey.

Edge, J. (2002). Continuing cooperative development. Ann Arbor, MI: University of Michigan Press. https://doi.org/10.3998/mpub.8915

Ewans, D. (2001). Observation of Teaching and Learning in Adult Education. London: LSDA.

Farrell, T. (2001). Critical friendship: colleagues helping each other develop. ELT Journal, 55(4), 368-374. https://doi.org/10.1093/elt/55.4.368

Flint, A. S., Zisook, K., \& Fisher, T. R. (2011). Not a one-shot deal: Generative professional development among experienced teachers. Teaching and Teacher Education, 27(8), 1163-1169. https://doi.org/10.1016/j.tate.2011.05.009

Freeman, D., \& Johnson, K. E. (1998). Reconceptualizing the Knowledge-Base of Language Teacher Education, TESOL Quarterly, 32(3), 397-417. https://doi.org/10.2307/3588114

Frels, R. K., \& Onwuegbuzie, A. J. (2013). Administering quantitative instruments with Qualitative Interviews: A mixed research approach. Journal of Counseling \&Development, 91(2), 184-194. https://doi.org/10.1002/j.1556-6676.2013.00085.x

Gillam, B. (2005). Research Interviewing: The Range of Techniques. Open University Press, McGraw Hill House

Gillham, B. (2007). Developing a Questionnaire. Continuum: London, UK.

Gosling, D. (2005). Some thoughts on sustaining POT over time. In Peer observation of teaching, 45-9. SEDA Paper., 118. London: Staff and Educational Development Association.

Hammersley-Fletcher, L., \& Orsmond, P. (2004). Evaluating our peers: Is peer observation a meaningful process? Studies in Higher Education, 29 (A), 489-503.

Heigham, J., \& Croker, R. A. (Eds.). (2009). Qualitative research in applied linguistics: A practical introduction. 
London: Palgrave Macmillan. https://doi.org/10.1057/9780230239517

Hong, J. A., \& Espelage, D. L. (2011). A review of mixed methods research on bullying and peer victimization in school. Educational Review, 64(1), 115-126. https://doi.org/10.1080/00131911.2011.598917

Johnstone, R. (2004). Language Teacher Education. In Davies, A., \& Elder, C. (eds.), The Handbook of Applied Linguistics, Blackwell Publishing Ltd. https://doi.org/10.1002/9780470757000.ch26

Karagiorgi, Y. (2012). Peer observation of teaching: perceptions and experiences of teachers in a primary school in Cyprus., Teacher Development: An international journal of teachers' professional development, 16(4), 443-461. https://doi.org/10.1080/13664530.2012.717210

Lomas, L., \& G. Nicholls. (2005). Enhancing teaching quality through peer review of teaching. Quality in Higher Education, 11(2), 137-49. https://doi.org/10.1080/13538320500175118

Malderez, A. (2003). Key Concepts in ELT: Observation ELT Journal, 57(2),179-181.

Mann, S. (2005). The language teacher's development. Language Teaching, 38(3), 103-118. https://doi.org/10.1017/S0261444805002867

Marshall, B. (2004). Learning from the academy: From peer observation of teaching to peer enhancement of learning and teaching. The journal of Adult Theological Education, 1(2), 185-204. https://doi.org/10.1558/jate.1.2.185.65573

Martin, G. A., \& Double, J. M. (1998). Developing higher education teaching skills through peer observation and collaborative reflection. Innovations in Education and Training International, 35(2), 161-170. https://doi.org/10.1080/1355800980350210

McMeniman, M., J. Cumming, J. Wilson, J. Stevenson \& C. Sim (2003). Teacher knowledge in action: the impact of educational research. Department of Education, Training and Youth Affairs, Australia.

Miller, P. (2004). Review of 'values in English language teaching'. TESOL-EJ, 7(2).

Montgomery, D. (1999). Teacher Appraisal through Classroom Observation. London: David Fulton.

Motallebzadeh, K., Hosseinnia, M., \& Domskey, G.H. J. (2017)., Peer observation: A key factor to improve Iranian EFL teachers' professional development. Cogent Education, 4. https://doi.org/10.1080/2331186X.2016.1277456

Namaghi, S, O. (2011). Theorizing Language Teachers"e Perceptions of the Rationales and Methods of Classroom Observation. US-China Foreign Language. David Publishing, 9(3), 147-157.

Opfer, V.D., \& Pedder, D. (2011). Conceptualizing teacher professional learning. Review of educational research, 81(3), 376-407. https://doi.org/10.3102/0034654311413609

Peel, D. (2005). Peer Observation as a transformatory tool. Teaching in Higher Education, 10(4), 489-504. https://doi.org/10.1080/13562510500239125

Quinlan, K. M., \& Akerlind, G. S. (2000). Factors affecting departmental peer collaboration for faculty development: Two cases in context. Higher Education, 40, 23-52. https://doi.org/10.1023/A:1004096306094

Rhodes, C., Stokes, M., \& Hampton, G. (2004). A Practical Guide to Mentoring, Coaching and Peer-Networking: Teacher professional development in schools and colleges. Routledge Falmer 11 New Fetter Lane, London EC4P 4EE.

Richards, J.C., \& Farrell, T.S.C. (2005). Professional Development for Language Teachers. Cambridge University Press. https://doi.org/10.1017/CBO9780511667237

Santos, L. M. D. (2016). Foreign Language Teachers' Professional Development through Peer Observation Programme. English Language Teaching, 9(10), 39-46. https://doi.org/10.5539/elt.v9n10p39

Shah, S. R. (2014). Empowering EFL teachers through distributed leadership: A critical perspective on leadership practices in an educational institution. International Journal of Business and Social Science, 5(10).

Shah, S. R., \& Al Harthi, K. (2014). TESOL classroom observations: a boon or a bane? An exploratory study at a Saudi Arabian university. Theory and Practice in Language Studies, 4(8), 1593. https://doi.org/10.4304/tpls.4.8.1593-1602

Shah, S. R., Hussain, M. A., \& Nasseef, O. A. (2013). Factors Impacting EFL Teaching: An Exploratory Study in the Saudi Arabian Context. Arab World English Journal, 4(3), 104-123. 
Sheal, P. (1989). Classroom observation: training the observers. ELT Journal, 43(2), 92-103. https://doi.org/10.1093/elt/43.2.92

Shortland, S. (2004). Peer Observation: a tool for staff development or compliance? Journal of Further and Higher Education, 28(2), 219-228.

Stillwell, C. (2009). The collaborative development of teacher training skills. ELT Journal, 63(4), 353-362. https://doi.org/10.1093/elt/ccn068

Syed, Z. (2003). The sociocultural context of English language teaching in the Gulf. TESOL Quarterly, 37(2), 337-341. https://doi.org/10.2307/3588508

Wallace, M. (2001). Training Foreign Language Teachers. Cambridge University Press: Cambridge, UK.

Webb, G. (1996). Understanding staff development. Buckingham: The Society for Research into Higher Education \& the Open University Press.

Webster-Wright, A. (2009). Reframing professional development through understanding authentic professional learning. Review of educational research, 79(2), 702-739. https://doi.org/10.3102/0034654308330970

Wilson, S.M., Rozelle, J.J., \& Mikeska, J.N. (2011). Cacophony or embarrassment of riches: building a system of support for quality teaching. Journal of teacher education, 62(4), 383-394. https://doi.org/10.1177/0022487111409416

Wong, H. (2004). The First Days of School: How to Be an Effective Teacher. Harry Wong Publications: Mountain View.

Write, T., \& Bolitho, R. (2007). Trainer development. Lulu.com.

Yost, D. S., Sentner, S. M., \& Forlenza-Bailey. A. (2000). An examination of the construct of critical reflection: Implications for teacher education programming in the 21st century. Journal of Teacher Education, 51, 39-49. https://doi.org/10.1177/002248710005100105 